\title{
The analysis report of surgical treatment of limb deformity and disability: 35,075 cases
}

\author{
J. Zang ${ }^{1,3}$, S. Qin ${ }^{2,3}$ \\ ${ }^{1}$ School of Population Medicine and Public Health, Chinese Academy of Medical Sciences/Peking Union Medical College, Beijing, China \\ ${ }^{2}$ Rehabilitation Hospital of the National Research Center for Rehabilitation Technical Aids, Key Laboratory of Intelligent Control and Rehabilitation \\ Technology of the Ministry of Civil Affairs, Beijing Key Laboratory of Rehabilitation Technical Aids for Old-Age Disability, Beijing, China \\ ${ }^{3}$ Qinsihe Orthopedic Institute, Beijing, China
}

\begin{abstract}
Objective To investigate the incidence characteristics and corrective strategies of various limb deformities treated by Qinsihe orthopaedic team in the past 40 years, so as to provide a large sample for understanding the causes, types and treatment methods of limb deformity and disability in China. Method A total of 35,075 cases were treated by Qinsihe orthopaedic team from May 1978 to December 2018. The age, gender, deformity characteristics, etiological and pathological composition, regional distribution and surgical methods of the patients were statistically analyzed. Results There were 20,458 males and 14,617 females. The age was 1 year to 82 years old, average 20.5 years. The majority of subjects were from 11 to 25 years old or 19,363 cases $(63 \%)$. There were 33,259 cases $(94.82 \%)$ of interventions on lower extremity. The geographical distribution of patients covers all the provinces, municipalities directly under the central government, autonomous regions in China and 12 foreign countries. There were 202 etiologies involving neurological, heredity, metabolism, traumatic sequelae, congenital, vascular, lymphoid, skin, endocrine, iatrogenic and so on. The top six deformities were due to poliomyelitis sequelae, cerebral palsy, traumatic sequelae, spondylolysis sequelae, genu varus\&valgus, congenital talipes equinovarus. There were 280 kinds of surgical methods, the majority of which were Achilles tendon lengthening, supracondylar osteotomy, subtalar joint arthrodesis, tibiofibular osteotomy, metatarsal aponeurosis and Achilles tendon replacement of peroneal longus muscle, etc. 8,702 cases were treated by orthopedic surgery combined with external fixation, including the Ilizarov fixator in 3,696 cases and hybrid fixator in 5,006 cases. Conclusion Qinsihe orthopaedic database with a history of 40 years is the largest one of limb deformity and disability in China. It reflects the etiology, type, population characteristics, surgical methods and strategy of limb disability and deformity, which can be treated by orthopaedic surgery. The data is a great treasure for orthopaedics and disability medicine in China and worldwide, and its important academic value and historical significance need to be further excavated and deep studied in future.
\end{abstract}

Keywords: orthopedics, Ilizarov technique, limb deformity, data base, analyses

Since 1978 for 40 years, the Qinsihe orthopedic team has operated on 35,075 patients with limb deformity and disability. In order to facilitate retrieval, an electronic database including clinical treatment data and imaging data of patients was established by the end of 2018. The Ilizarov techniques played an important role in the formation of treatment effect and development of this database. The purpose of this study was to analyze the data of this database, and to understand the characteristics, etiology, disease types and current status of limb deformities and disabilities in China and to explain the value of the development of the Ilizarov technique.

\section{DATA AND METHODS}

The clinical data of 35,075 patients who underwent surgical treatment from May 25, 1978 to December 31, 2018 were retrospectively analyzed. The gender, age at operation, geographical distribution, etiology and disease composition, deformity characteristics, surgical site and surgical methods of the patients were statistically analyzed. Among them, each patient hospitalized once was recorded as one case, and more than one operation during one hospitalization was still counted as one case; multiple hospitalized operations at different times were recorded as multiple cases.
The statistical results are divided into subgroups according to the current clinical disciplines, such as neurogenic diseases (central and peripheral), congenital and genetic diseases, infectious diseases (bacteria, viruses), trauma and burns, immune metabolic diseases, tumors, vascular diseases blood diseases, bone and joint cumulative damage and degenerative diseases, muscle diseases, degenerative diseases caused by other rare diseases. The top 20 diseases were summarized and the top 20 methods of lower limb surgeries were statistically analyzed. 
Among 35,075 patients, there were 20,458 males $(58.33 \%)$ and 14,617 females $(41.67 \%)$; the ratio was $1.4: 1$. The patients were aged from 1 to 82 years, with an average age of 20.5 years old; the patients were mainly 11 to 25 years old, with 19,363 cases, accounting for $63 \%$; the detailed age distribution was shown in Table 1. The patients came from all provinces, municipalities, autonomous regions and 12 foreign countries except Macao (Tables 2 and 3). 202 etiological diseases were involved, including neurology, genetics, metabolism, traumatic sequelae, congenital, vascular, lymphatic, skin, endocrine and iatrogenic diseases, admitted to more than 10 different departments (Table 4-10). The main diseases include poliomyelitis sequelae and cerebral palsy, trauma

Table 1

Age distribution

\begin{tabular}{|c|c|}
\hline Age (years) & Cases (percentage \%) \\
\hline $1 \sim 5$ & $1.981(5.65)$ \\
\hline $6 \sim 10$ & $5.322(15.17)$ \\
\hline $11 \sim 15$ & $5.975(17.03)$ \\
\hline $16 \sim 20$ & $7.072(20.16)$ \\
\hline $21 \sim 25$ & $6.316(18.01)$ \\
\hline $26 \sim 30$ & $3.978(11.34)$ \\
\hline $31 \sim 35$ & $2.214(6.31)$ \\
\hline $36 \sim 40$ & $1.086(3.10)$ \\
\hline $41 \sim 50$ & $781(2.23)$ \\
\hline $51 \sim 60$ & $271(0.77)$ \\
\hline $61 \sim 70$ & $67(0.19)$ \\
\hline $71 \sim 80$ & $10(0.03)$ \\
\hline$>80$ & $2(0.01)$ \\
\hline
\end{tabular}

Table 3

Cases of foreign patients

\begin{tabular}{|c|c|}
\hline Nation & Cases (n) \\
\hline Russia & 5 (operated in Russia) \\
\hline Indonesia & 2 \\
\hline Syria & 2 \\
\hline Romania & 1 \\
\hline Saudi Arabia & 1 \\
\hline Hungary & 2 \\
\hline U.S.A & 2 \\
\hline Mongolia & 1 \\
\hline Vietnam & 1 \\
\hline Kazakhstan & 1 \\
\hline South Africa & 1 \\
\hline Palestine & 20 \\
\hline Total & \\
\hline
\end{tabular}

sequelae, spina bifida sequelae, genu varus \& genu valgus and congenital clubfoot (Table 11).

The number of operations from 1978 to 2018 was shown in Figure 1. The locations of operations were 575 upper limb cases (1.64\%), 33,259 lower limb cases $(94.82 \%)$ and 1,242 cases $(3.54 \%)$ on neck and spine. According to statistics, a total of 280 kinds of surgical methods were used in the Qinsihe orthopedics in the past 40 years, including tendon / fascia release, tendon transposition, osteotomy, bone lengthening, joint fixation, brace assisted distraction, etc. (Table 12). There were 8,702 cases of orthopedic surgery combined with external fixation, including 3,696 cases of Ilizarov ring external fixation and 5,006 cases of hybrid external fixation.

Table 2

Region distribution of Chinese patients

\begin{tabular}{|c|c|}
\hline Region & Cases (n) \\
\hline Beijing & 1.742 \\
\hline Tianjin & 156 \\
\hline Shanghai & 85 \\
\hline Chongqing & 74 \\
\hline Heilongjiang & 7.471 \\
\hline Jilin & 446 \\
\hline Liaoning & 474 \\
\hline Inner Mongolia & 496 \\
\hline Hebei & 1.632 \\
\hline Shanxi & 715 \\
\hline Henan & 4.076 \\
\hline Shandong & 2.943 \\
\hline Jiangsu & 526 \\
\hline Anhui & 1.177 \\
\hline Hubei & 3.185 \\
\hline Hunan & 1.488 \\
\hline Jiangxi & 2.664 \\
\hline Zhejiang & 560 \\
\hline Fujian & 714 \\
\hline Guangdong & 541 \\
\hline China Taiwan & 1 \\
\hline Hainan & 59 \\
\hline Guangxi & 122 \\
\hline Guizhou & 167 \\
\hline Yunnan & 139 \\
\hline Sichuan & 331 \\
\hline Shanxi & 1.499 \\
\hline Gansu & 1.042 \\
\hline Ningxia & 84 \\
\hline Qinghai & 104 \\
\hline Xinjiang & 314 \\
\hline Tibet & 27 \\
\hline Hong Kong & 1 \\
\hline Total & 35.055 \\
\hline
\end{tabular}


Case distribution of limb deformity caused by central nervous system disease sequalae

\begin{tabular}{|l|c|}
\hline \multicolumn{1}{|c|}{ Category } & Cases (n) \\
\hline Sequelae of cerebral palsy & 4.670 \\
\hline Sequelae of encephalitis & 72 \\
\hline Sequelae of brain trauma & 62 \\
\hline Sequelae of hydrocephalus & 21 \\
\hline Sequelae of acute myelitis & 20 \\
\hline Sequelae of incomplete paraplegia after spinal cord injury & 5 \\
\hline sequela of stroke & 4 \\
\hline Spastic deformity of foot and ankle caused by drug-induced spinal cord poisoning & 3 \\
\hline Sequelae of hepatolenticular degeneration & 3 \\
\hline Limb deformity caused by craniopharyngioma & 2 \\
\hline Deformity of lower limbs caused by compression of thoracic spinal cord & 2 \\
\hline Spinal cord spasmodic lower extremity deformity & 2 \\
\hline Sequelae of spinal arachnoiditis & 1 \\
\hline Limb deformity of incomplete spinal cord injury caused by ossification of cervical posterior longitudinal ligament & 1 \\
\hline Limb deformity in Parkinson's disease & 1 \\
\hline Foot deformity after intracranial cyst surgery & 1 \\
\hline Sequelae of subarachnoid hemorrhage & 1 \\
\hline Epilepsy sequelae & 1 \\
\hline Sequelae of cerebral arachnoiditis & 1 \\
\hline Total & \\
\hline
\end{tabular}

Table 5

Case distribution of limb deformity caused by peripheral nervous disease sequalae

\begin{tabular}{|l|c|}
\hline \multicolumn{1}{|c|}{ Category } & Cases (n) \\
\hline Spina bifida lower limb deformity & 910 \\
\hline Scoliosis limb deformity & 48 \\
\hline Sequelae of lateral sclerosis & 33 \\
\hline Sequelae of obstetric paralysis & 21 \\
\hline Sequelae of sciatic nerve injury & 16 \\
\hline Limb deformity in ankylosing spondylitis & 4 \\
\hline Sequelae of spinal nerve (root) injury & 3 \\
\hline Sequelae of radial nerve paralysis & 2 \\
\hline Total & 1.037 \\
\hline
\end{tabular}

Table 6

Case distribution of limb deformity caused by congenital deformity

\begin{tabular}{|l|c|}
\hline \multicolumn{1}{|c|}{ Category } & Cases (n) \\
\hline Congenital clubfoot & 715 \\
\hline Developmental dysplasia of the hip & 542 \\
\hline Congenital multiple joint contracture & 134 \\
\hline Congenital fibula hemimelia & 100 \\
\hline Congenital pseudarthrosis of tibia & 84 \\
\hline Congenital dislocation of patella & 55 \\
\hline Congenital coxa varus & 48 \\
\hline Congenital shortening of lower extremity & 37 \\
\hline Absence of radius & 21 \\
\hline Multiple epiphyseal dysplasia & 20 \\
\hline Congenital hallux foot deformity & 19 \\
\hline Multiple chondrodysplasia & 17 \\
\hline Congenital pterygoid knee joint & 15 \\
\hline Congenital vertical talus & 14 \\
\hline Congenital tibial hemimelia & 12 \\
\hline others & 116 \\
\hline Total & 1.949 \\
\hline
\end{tabular}

Case distribution of limb deformity caused by genetic diseases

\begin{tabular}{|l|c|}
\hline \multicolumn{1}{|c|}{ Category } & Cases (n) \\
\hline Hereditary sensorimotor disease & 224 \\
\hline Diaphyseal sequestration & 28 \\
\hline Hereditary spastic paraplegia & 20 \\
\hline Progressive muscular dystrophy & 17 \\
\hline Familial neurofibromatosis & 13 \\
\hline Familial cavus & 6 \\
\hline Trifunctional protein deficiency & 1 \\
\hline Myositis ossificans progressiva & 1 \\
\hline Hereditary chondrodysplasia & 1 \\
\hline Sequelae of cerebral cavernous degeneration & 1 \\
\hline Total & 312 \\
\hline
\end{tabular}

Table 8

Case distribution of limb deformity caused by bacterial infection diseases

\begin{tabular}{|l|c|}
\hline \multicolumn{1}{|c|}{ Category } & Cases (n) \\
\hline Chronic osteomyelitis & 95 \\
\hline Sequelae of suppurative arthritis & 52 \\
\hline Sequelae of meningitis & 35 \\
\hline Sequelae of bone tuberculosis & 18 \\
\hline Sequelae of sepsis & 7 \\
\hline Sepsis sequelae & 3 \\
\hline Sequelae of cerebral tuberculoma & 2 \\
\hline Sequelae of transverse myelitis & 2 \\
\hline Tetanus sequelae & 2 \\
\hline Sequelae of toxic bacillary dysentery & 1 \\
\hline Sequelae of typhoid & 1 \\
\hline Sequelae of gastrocnemius infection & 1 \\
\hline Sequelae of synovial tuberculosis & 1 \\
\hline Sequelae of lumbar tuberculosis & 1 \\
\hline Sequelae of tuberculous meningitis & 1 \\
\hline Sequelae of choroiditis & 1 \\
\hline Total & 223 \\
\hline
\end{tabular}


Senij Ortopedii, Vol. 27, no 3, 2021

Table 9

Table 10

Case distribution of limb deformity caused by virus and fungal infection

\begin{tabular}{|l|c|}
\hline \multicolumn{1}{|c|}{ Category } & Cases (n) \\
\hline Sequelae of Poliomyelitis & 23,520 \\
\hline Sequelae of Guillain Barre syndrome & 83 \\
\hline Sequelae of epidemic encephalitis B & 11 \\
\hline Sequelae of hand foot mouth disease & 9 \\
\hline Sequelae of mildewed sugarcane poisoning & 1 \\
\hline Total & 23,624 \\
\hline
\end{tabular}

Limb deformity caused by trauma and burn injury

\begin{tabular}{|l|c|}
\hline \multicolumn{1}{|c|}{ Category } & Cases (n) \\
\hline Post-traumatic stress disorder & 917 \\
\hline Sequelae of common peroneal nerve paralysis & 64 \\
\hline $\begin{array}{l}\text { Developmental deformity of lower limbs } \\
\text { caused by epiphyseal injury }\end{array}$ & 42 \\
\hline Bone defect & 35 \\
\hline Nonunion & 34 \\
\hline Sequelae of burn & 29 \\
\hline Sequelae of common peroneal nerve injury & 17 \\
\hline $\begin{array}{l}\text { Residual deformity of replantation of amputated } \\
\text { limb }\end{array}$ & 1 \\
\hline Total & 1,139 \\
\hline
\end{tabular}

Table 11

Number of diseases involved (Top 20)

\begin{tabular}{|l|c|c|}
\hline \multicolumn{1}{|c|}{ Category } & Cases (\%) & Age (year, verage) \\
\hline Sequelae of polio & $23,520(67.06)$ & $1 \sim 71(20.60)$ \\
\hline Sequelae of cerebral palsy & $4,670(13.31)$ & $3 \sim 84(22.41)$ \\
\hline post-traumatic disorder & $918(2.62)$ & $1 \sim 50(18.25)$ \\
\hline Sequelae of spina bifida & $910(2.59)$ & $2 \sim 67(22.21)$ \\
\hline Genu varus and genu valgus & $724(2.06)$ & $1 \sim 60(12.56)$ \\
\hline Congenital clubfoot & $716(2.04)$ & $1 \sim 48(12.76)$ \\
\hline Developmental dislocation of hip & $542(1.55)$ & $3 \sim 42(14.73)$ \\
\hline Gluteal muscle contracture lower limb deformity & $231(0.66)$ & $4 \sim 65(21.74)$ \\
\hline Limb deformity in sensorimotor neuron disease & $224(0.64)$ & $1 \sim 32(10.93)$ \\
\hline arthrogryposis multiplex congenita & $134(0.38)$ & $3 \sim 52(23.21)$ \\
\hline Chronic osteomyelitis & $95(0.27)$ & $1 \sim 40(11.05)$ \\
\hline Congenital fibular hemiarthroplasty & $95(0.27)$ & $2 \sim 47(13.27)$ \\
\hline Congenital pseudarthrosis of tibia & $84(0.24)$ & $2 \sim 47(19.80)$ \\
\hline Guillain-Barre Syndrome & $83(0.24)$ & $4 \sim 53(19.60)$ \\
\hline Rickets & $75(0.21)$ & $4 \sim 39(16.49)$ \\
\hline Sequelae of encephalitis & $73(0.21)$ & $4 \sim 63(24.56)$ \\
\hline Iatrogenic limb deformity & $70(0.20)$ & $2 \sim 41(15.78)$ \\
\hline Muscular torticollis & $66(0.19)$ & $1 \sim 56(14.87)$ \\
\hline Common peroneal nerve palsy limb deformity & $64(0.18)$ & $6 \sim 49(21.75)$ \\
\hline Sequelae of brain injury & $62(0.18)$ & \\
\hline
\end{tabular}

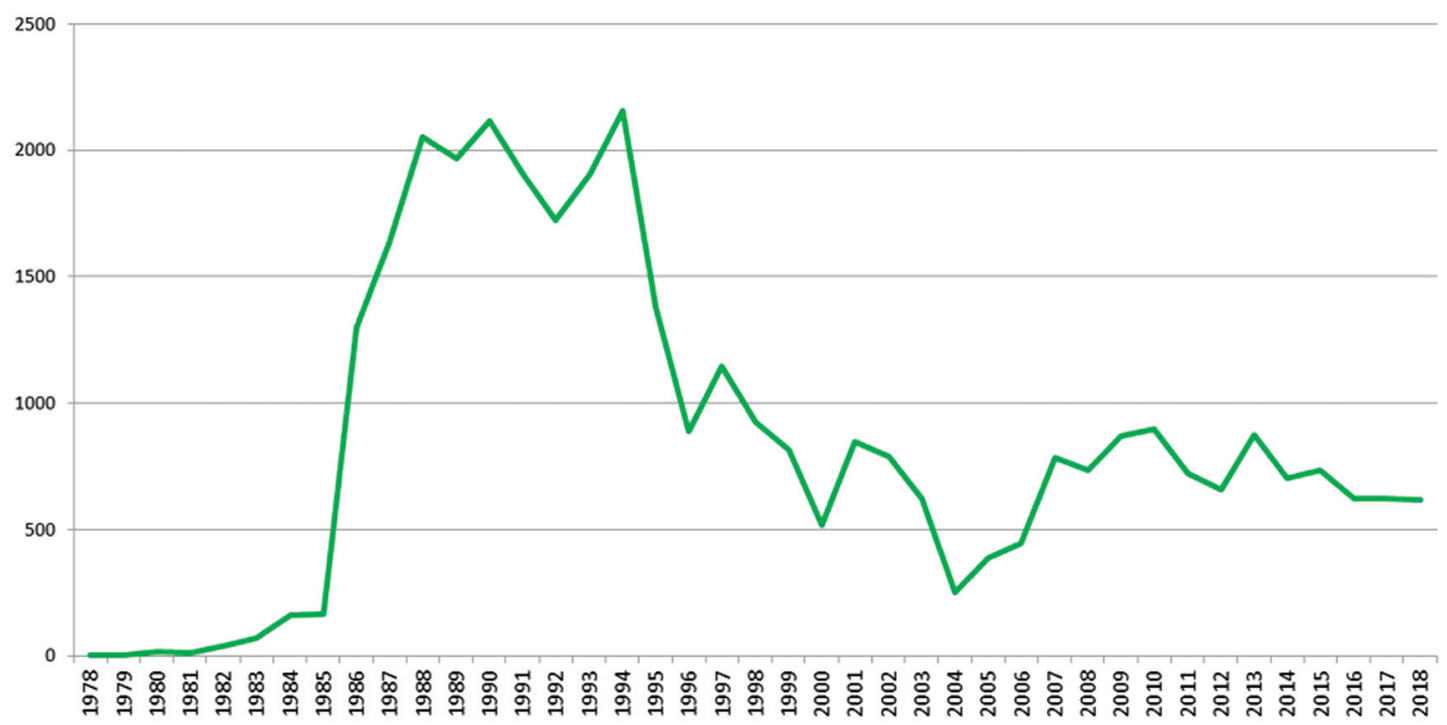

Fig. 1. Surgical cases per year (n) 
Surgical method used (Top 20)

\begin{tabular}{|l|c|}
\hline \multicolumn{1}{|c|}{ Category } & Cases (n) \\
\hline Achilles tendon lengthening & 7,868 \\
\hline Supracondylar osteotomy of femur & 7,356 \\
\hline Calcaneotalar arthrodesis & 6,292 \\
\hline Tibiofibular osteotomy & 4.167 \\
\hline Release of plantar aponeurosis & 3.672 \\
\hline Transposition of peroneus longus to replace Achilles tendon & 2.545 \\
\hline Transposition of external oblique abdominis to replace gluteus medius & 2.381 \\
\hline Release of hip flexion deformity & 2.370 \\
\hline Triple Arthrodesis & 2.291 \\
\hline Partial release of adductor femoris at the starting point & 1.961 \\
\hline Lengthening of posterior tibial tendon & 1.807 \\
\hline Knee flexion release & 1.715 \\
\hline Osteotomy of the first metatarsal base & 1.397 \\
\hline Distal subcutaneous amputation of gracilis tendon & 1.165 \\
\hline Osteotomy and lengthening of tibia and fibula & 1.138 \\
\hline Transposition of peroneus brevis to replace Achilles tendon & 1.040 \\
\hline Anterior external placement of posterior tibial muscle & 1.010 \\
\hline Dissection of common carotid artery adventitia sympathetic network & 978 \\
\hline Iliotibial tract release & 900 \\
\hline Transposition of sacrospinalis muscle to replace gluteus muscle & 885 \\
\hline
\end{tabular}

\section{DISCUSSION}

In May 1978, Dr. Qin Sihe successfully carried out his first case of deformity correction of clubfoot in Miaoshan hospital of Laiwu city, Shandong Province, and thus embarked on the road of orthopedics [1]. From the beginning of the implementation of orthopedic surgery, a habit has been formed that all patients who have been treated by him and his team routinely fill in a form before surgery, and every 100 copies can be kept in a file. In the past 40 years, although many units changed, the habit of accumulating the data of cases has never changed. Since 2013, cases collection has been introduced electronically. To December 31, 2018, 35,075 cases have been collected. Among them, $94.82 \%$ were lower limb and ankle deformity correction. Some congenital, hereditary, metabolic and acquired severe complex limb deformities were recorded, and many overseas patients also were attracted for medical treatment. Therefore, the data of limb deformities is a wealth in the medical field, especially for lower limb deformity correction.

Through the preliminary analysis of clinical data of 35,075 patients, the results showed that there were significantly more male patients than female ones, which may be related to China's long-term implementation of Family Planning, rural families pay more attention to boys, and their limb deformity and disability got more opportunities for treatment. The range of age for treatment is wide, but young people prevail, of which $81.71 \%$ are patients aged 6-30. It can be seen that young people with limb deformity, especially lower limb deformity, are the main population receiving orthopedic surgery, which is related to the large amount of exercise, high requirements for participating in social activities, strong requirements for recovering health and improving function. The year period with the largest number of operations was 1988-1994, which was the time when the state implemented Salvage Surgery for Poliomyelitis sequelae. Dr. Qin served as the director of two centers for poliomyelitis sequelae correction in Heilongjiang province and Beijing city, and presided over the operation correction tasks of the two provinces and cities. According to the geographical distribution, there were 7,471 cases of surgical patients from Heilongjiang province, accounting for $21.30 \%$ of all patients. It was related to the fact that Qin had worked in Heilongjiang province for 5 years and carried out a large number of surgeries.

More than 10 disciplines were covered in this group of limb deformities and disabilities, including gynecology, pediatrics, nerve, blood, tumor, skin, immunity, etc., covering almost all sub-disciplines of orthopedics with 202 diseases. It was difficult to determine the etiology in some limb deformities. The top six deformities were poliomyelitis sequelae, cerebral palsy, trauma sequelae, spina bifida sequelae, genu varus, genu valgus, congenital clubfoot, which reflected the incidence of the main diseases of lower limb deformity to a certain extent. In the disease spectrum, the sequelae of poliomyelitis have been 
gradually replaced by cerebral palsy, traumatic limb deformity and lower limb deformity due to spina bifida.

There were 280 kinds of surgical methods, including tendon/fascia release, tendon transposition osteotomy, bone lengthening, joint fixation, bone traction, brace assisted stretching, etc. The most commonly used operations include Achilles tendon lengthening, supracondylar osteotomy of femur, calcaneal talar joint fusion, tibiofibular osteotomy, plantar aponeurosis release and peroneal longus tendon replacement. The most common causes were ankle deformity and sequelae of poliomyelitis $[2,3]$.

The combination of Ilizarov technology and these operations was a revolution in the history of orthopedic surgery, which greatly improved the surgical safety and clinical treatment effect [4-6]. Among them, osteogenesis imperfecta, scleroderma, congenital tibial hemimelia and other diseases were all managed with external fixators. Based on Chinese culture, Qin orthopedic team has been continuously exploring, practicing and summarizing the surgical experience in the management of limb deformities and disabilities. Based on the research and application of the Ilizarov technology, the team has put forward and practiced the "Natural reconstruction orthopedics [7]" and the principle of "One walk, Two lines and Three balances", which in turn guide the clinical practice in orthopedics and form a new model to establish orthopedic technology theory system with distinctive characteristics. It emphasizes the static balance and the dynamic balance in treatment and rehabilitation. It is able to cure severe and complex limb deformities with relatively simple means of diagnosis and treatment. It enables hundreds of patients with limb deformities who crawl, squat or rely on wheelchairs to walk upright, and cures a number of limb deformities on the verge of amputation.

The preliminary statistical results of 35,075 cases of limb deformities reflect the etiology, disease types, population characteristics and surgical methods used for limb deformities at present. These data with great academic value and historical significance for limb reconstruction are a treasure house of orthopedics for China and the world.

The research supported by project of Operation funds of key laboratory of rehabilitation of Ministry of Civil Affairs(No 120603020068).

Conflict of interest All authors declare that there is no conflict of interest in the course of research and article writing.

Institutional ethical issues Approved by the Ethics committee of Rehabilitation hospital of National Research Center for Rehabilitation Technical Aids.

Acknowledgement Thanks to Yilan Wang for organizing and counting the data.

\section{REFERENCES}

1. Qin S. Inspiration from the 33 year follow-up results of a case of triple arthrodesis. Chinese Journal of Orthopedics, 2013, vol. 21, no. 19, pp. 2007-2008.

2. Qin S., Chen J., Zheng X. et al. Statistical analysis of 12840 cases of poliomyelitis sequelae. Chinese Journal of Orthopedics, 2004 , vol. 9, pp. 17-23.

3. Surgical treatment of poliomyelitis sequelae. ${ }^{\text {st }}$ Ed. Qin S., editor. Beijing, People's Health Publishing House, 2006 , pp. 3-8.

4. Qin S., Guo B., Jiao S., Zang J., Zhang L., Wang Y., Zheng X., Shi L., Qin X. [Data analysis of 8113 cases of limb deformities corrected by external fixation]. Zhongguo Xiu Fu Chong Jian Wai Ke Za Zhi [Chinese Journal of Repair and Reconstruction Surgery], 2018, vol. 32, no. 10, pp. 1241-1248. (in Chinese) DOI: 10.7507/1002-1892.201807055

5. Qin S.H., Guo B.F., Zheng X.J., Jiao S.F., Xia H.T., Peng A.M., Pan Q., Zang J.C., Wang Z.J. [Domestic external fixator application in the treatment of limb deformities: 7289 cases application report]. Zhonghua Wai Ke Za Zhi [Chinese Journal of Surgery], 2017, vol. 55, no. 9. pp. 678-683. (in Chinese) DOI: 10.3760/cma.j.issn.0529-5815.2017.09.008

6. Limb lengthening and reconstruction. $1^{\text {st }}$ Ed. Qin S., Jiao S., Shu H., eds. Beijing, People's Military Medical Press, 2017 , pp. 48-68.

7. Zang J.C., Qin S.H. [From Wolff law, Ilizarov technology to natural reconstruction theory]. Zhongguo Gu Shang [Orthopedics and Traumatology of China], 2013, vol. 26, no. 4, pp. 287-290. (in Chinese)

8. Lower Limb Deformities: Deformity Correction and Function Reconstruction. Chapter 2. Qin S., Zang J., Jiao S., Pan Q., eds. Springer Singapore, 2020, pp. 45-66. DOI: 202010.1007/978-981-13-9604-5

Received: 08.04.2021

Information about the authors:

1. Jiancheng Zang,

School of Population Medicine and Public Health, Chinese Academy of Medical Sciences/Peking Union Medical College, Beijing, China,

Qinsihe Orthopedic Institute, Beijing, China

2. Sihe Qin,

Department of Orthopaedics, Rehabilitation Hospital of the National Research Center for Rehabilitation Technical Aids, Key

Laboratory of Intelligent Control and Rehabilitation Technology of the Ministry of Civil Affairs, Beijing Key Laboratory of

Rehabilitation Technical Aids for Old-Age Disability Beijing, 100176, P. R. China,

Qinsihe Orthopedic Institute, Beijing, China,

Email: qinsihe@163.com 